\title{
Lapillicoccus jejuensis gen. nov., sp. nov., a novel actinobacterium of the family Intrasporangiaceae, isolated from stone
}

Correspondence Soon Dong Lee sdlee@cheju.ac.kr

\author{
Soon Dong Lee and Dong Wan Lee
}

Department of Science Education, Cheju National University, Jeju 690-756, Republic of Korea

\begin{abstract}
A novel, yellow-pigmented actinobacterium was isolated from a small stone collected in Jeju, Republic of Korea. The cells of the organism, designated strain R-Ac013 ${ }^{\top}$, were Gram-positive, aerobic, non-motile cocci that occurred singly or in pairs. The strain showed growth at $10-37{ }^{\circ} \mathrm{C}$ and $\mathrm{pH} 4.1-11.1$, and tolerated $2 \% \mathrm{NaCl}$. On the basis of the 16S rRNA gene sequence, the organism was phylogenetically related to members of the genera Tetrasphaera (94.6-97.1\% sequence similarity), Terrabacter (96.5\%), Knoellia (96.4\%), Terracoccus (96.4\%), Oryzihumus (96.4\%), Janibacter (96.1-96.4\%) and Intrasporangium (96.2\%). The chemotaxonomic results for the organism were as follows: LL-diaminopimelic acid as the diagnostic diamino acid in the peptidoglycan, acetyl-type murein, $\mathrm{MK}-8\left(\mathrm{H}_{4}\right)$ as the major menaquinone, a DNA G+C content of $74.1 \mathrm{~mol} \%$, and a polar lipid profile that comprised diphosphatidylglycerol and phosphatidylinositol. The fatty acid profile consisted of iso- and anteiso-methyl-branched, straight-chain saturated and monounsaturated types, the major components being iso- $\mathrm{C}_{16: 0 \text {, }}$ $\mathrm{C}_{17: 1} \omega 8 \mathrm{c}$ and iso- $\mathrm{C}_{15: 0}$. The combination of the phenotypic and phylogenetic data revealed that this strain represents a novel genus and species of the family Intrasporangiaceae, for which the name Lapillicoccus jejuensis gen. nov., sp. nov. is proposed. The type strain is strain R-Ac013 ${ }^{\top}\left(=\right.$ KCTC $19200^{\top}=$ DSM $\left.18607^{\top}\right)$.
\end{abstract}

The family Intrasporangiaceae (Stackebrandt et al., 1997; Stackebrandt \& Schumann, 2000) contains a variety of actinomycetes that have LL-diaminopimelic acid (LL-DAP), meso-diaminopimelic acid (meso-DAP) or L-ornithine as the diagnostic diamino acid in the cell-wall peptidoglycan (Martin et al., 1997; Maszenan et al., 2000; Hanada et al., 2002; Groth et al., 2002; Kageyama et al., 2005). At present, this family contains 13 genera with validly published names, including the recently described genera Phycicoccus (Lee, 2006) and Kribbia (Jung et al., 2006); these genera can be readily differentiated from one another on the basis of a combination of phenotypic and genotypic features. Of these genera, Arsenicicoccus (Collins et al., 2004), Intrasporangium (Kalakoutskii et al., 1967), Terrabacter (Collins et al., 1989) and Terracoccus (Prauser et al., 1997) contain LL-DAP as the diagnostic diamino acid in the cell-wall peptidoglycan. In this study, we describe the classification of an LL-DAPcontaining actinomycete (isolated from a small stone) by

Abbreviations: LL-DAP, LL-diaminopimelic acid; meso-DAP, mesodiaminopimelic acid.

The GenBank/EMBL/DDBJ accession number for the 16S rRNA gene sequence of strain R-Ac013 ${ }^{\top}$ is AM398397.

A transmission electron micrograph of cells of strain R-Ac013 ${ }^{\top}$ is available as supplementary material with the online version of this paper. means of a polyphasic approach; we propose that it represents a novel genus and species of the family Intrasporangiaceae.

Strain R-Ac0 $13^{\mathrm{T}}$ was isolated from a small stone collected from an agricultural field in Jeju, Republic of Korea. For the bacterial isolation, a piece of the stone was crushed into a powder (using a pestle) and suspended in $10 \mathrm{ml}$ sterilized, distilled water. Serial diluents of the sample were transferred onto starch-casein agar (Kuester \& Williams, 1964) and the plates then incubated at $30{ }^{\circ} \mathrm{C}$ for 14 days. The pure culture was maintained as a $20 \%$ glycerol suspension at -20 and $-80{ }^{\circ} \mathrm{C}$.

DNA extraction, PCR-amplification of the 16S rRNA gene and sequencing were performed as described by Lee \& Jeong (2006). An almost-complete 16S rRNA gene sequence $(1412 \mathrm{nt})$ for strain $\mathrm{R}-\mathrm{Ac} 013^{\mathrm{T}}$ was determined in this study and aligned with respect to the corresponding sequences of representatives of the family Intrasporangiaceae, using the program CLUSTAL_X (Thompson et al., 1997). Phylogenetic analyses were performed by using three tree-making algorithms, namely the neighbourjoining (Saitou \& Nei, 1987), maximum-likelihood (Felsenstein, 1981) and maximum-parsimony (Fitch, 1971) methods. A phylogenetic tree was constructed using 
the Jukes-Cantor coefficient (Jukes \& Cantor, 1969) and the neighbour-joining method (Saitou \& Nei, 1987). A bootstrap analysis (Felsenstein, 1985) was performed by using 1000 replicated datasets.

In total, 1342 unambiguous aligned nucleotides present in all strains were used for the phylogenetic analyses. A neighbour-joining tree (Fig. 1) based on the 16S rRNA gene sequence revealed that strain $\mathrm{R}-\mathrm{Ac} 013^{\mathrm{T}}$ occupied a phylogenetically distinct lineage within the family Intrasporangiaceae and formed a sub-branch between a Janibacter-Knoellia-Tetrasphaera cluster and an IntrasporangiumPhycicoccus-Terrabacter-Terracoccus cluster. However, this relationship was not supported by a high bootstrap value or with the two other tree-making methods used in this study. When the maximum-parsimony method was applied, strain R-Ac013 ${ }^{\mathrm{T}}$ was positioned at the periphery of an Intrasporangium-Phycicoccus-Terrabacter-Terracoccus cluster, but formed a sub-branch between an Ornithinicoccus hortensis-Oryzihumus leptocrescens cluster and Tetrasphaera japonica in the maximum-likelihood tree (data not shown). Strain R-Ac013 ${ }^{\mathrm{T}}$ revealed the highest $16 \mathrm{~S}$ rRNA gene sequence similarity value $(97.1 \%)$ with respect to Tetrasphaera japonica ACM $5116^{\mathrm{T}}$. Members of the genera Terrabacter ( $96.5 \%$ sequence similarity), Tetrasphaera (94.6-96.5\%), Knoellia (96.4\%), Terracoccus (96.4\%), Oryzihumus (96.4\%), Janibacter (96.1-96.4\%) and Intrasporangium (96.2\%) were also revealed as phylogenetic neighbours of strain R-Ac013 ${ }^{\mathrm{T}}$.

Temperature $\left(4-42{ }^{\circ} \mathrm{C}\right)$ and $\mathrm{pH}(4.1-12.1)$ ranges for growth were determined on ISP 2 medium (Shirling \& Gottlieb, 1966). The $\mathrm{pH}$ of the medium was adjusted (using increments of $1.0 \mathrm{pH}$ unit) before sterilization. $\mathrm{NaCl}$ tolerance for growth was tested at final concentrations of $1-9 \%(\mathrm{w} / \mathrm{v})$. For these tests, plates were incubated for 5 days at $28{ }^{\circ} \mathrm{C}$. Protease and cellulase activities were determined on ISP 2 medium supplemented with $1 \%$ (w/v) skimmed milk and $0.5 \%$ (w/v) CM-cellulose (Sigma), respectively. Degradation of hypoxanthine,

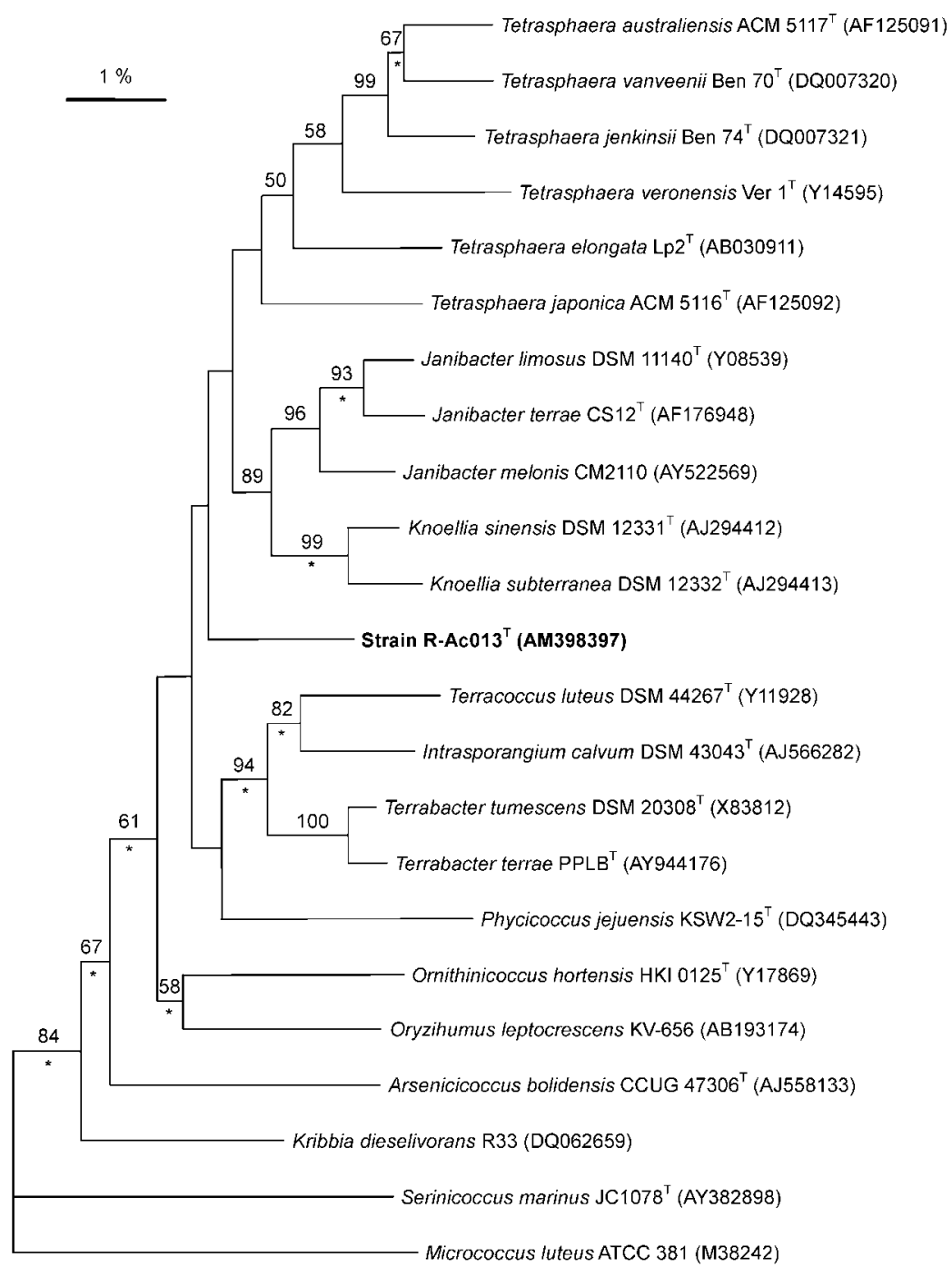

Fig. 1. Phylogenetic tree showing the relationships between strain R-Ac013 ${ }^{\top}$ and representatives of the family Intrasporangiaceae. The tree was constructed, using the neighbourjoining method, from evolutionary distances calculated with the Jukes-Cantor coefficient. Asterisks indicate branches that were also found in the maximum-likelihood and maximum-parsimony trees. Bootstrap percentages $(>50 \%)$, based on a neighbour-joining analysis of 1000 resampled datasets, are shown at nodes. Bar, 0.01 substitutions per nucleotide position. 
tyrosine and xanthine was investigated as described previously (Lee, 2006); the results were recorded after 14 days incubation at $28{ }^{\circ} \mathrm{C}$. The ability to hydrolyse DNA and starch was examined using DNase test agar (Difco) and starch agar (Difco), respectively, and was recorded as positive by the presence of transparent zones when plates were flooded with $1 \mathrm{M} \mathrm{HCl}$ and iodine solution, respectively. Gram staining was performed using a Gram 2 kit (bioMérieux) according to the manufacturer's instructions. Oxidase and catalase activities were tested as described previously (Lee, 2006). Tests with API 20NE and API ZYM strips (bioMérieux) were performed according to the manufacturer's instructions. Cell morphology and motility were observed using phase-contrast and transmission electron microscopy, using cells grown on trypticase soy agar (TSA; Difco) for 3 days at $28{ }^{\circ} \mathrm{C}$. To check for the presence of flagella, cells were negatively stained with $1 \%$ (w/v) phosphotungstic acid and observed with a JEOL 1200EXII transmission electron microscope. Colony morphology and pigmentation were usually observed using cells grown on TSA for 7 days at $28{ }^{\circ} \mathrm{C}$. The cells of strain $\mathrm{R}-\mathrm{Ac} 013^{\mathrm{T}}$ were found to comprise Gram-positive, aerobic, catalase-positive, oxidase-negative, non-endospore-forming, non-motile cocci that occurred singly or in pairs (see Supplementary Fig. S1, available in IJSEM Online). Colonies were circular, flat, undulate and bright yellow in colour, reaching $0.6-1.1 \mathrm{~mm}$ in diameter after 7 days incubation. Other physiological and biochemical properties are given in the genus/species descriptions.

Cell biomass for chemotaxonomic analyses was obtained from cells grown in trypticase soy broth (Difco) for 3 days at $28{ }^{\circ} \mathrm{C}$. The following chemotaxonomic characteristics of strain $\mathrm{R}-\mathrm{Ac} 013^{\mathrm{T}}$ were determined as described by Lee (2006): the diaminopimelic acid isomer in the peptidoglycan, the acyl type of the murein, the menaquinones, the polar lipids and the presence of any mycolic acids. Strain $\mathrm{R}-\mathrm{Ac} 013^{\mathrm{T}}$ contained LL-DAP as the diagnostic diamino acid in the peptidoglycan. The phospholipids were diphosphatidylglycerol and phosphatidylinositol. The major menaquinone $\left(66 \%\right.$ of the total) was MK- $8\left(\mathrm{H}_{4}\right)$; small amounts of MK- $9\left(\mathrm{H}_{0}\right)(12 \%)$, MK- $7\left(\mathrm{H}_{0}\right)(12 \%)$ and MK$8\left(\mathrm{H}_{2}\right)(8 \%)$ were also detected. The DNA G $+\mathrm{C}$ content of strain R-Ac013 ${ }^{\mathrm{T}}$, determined by HPLC (as described by Mesbah et al., 1989), was $74.1 \mathrm{~mol} \%$.

The cellular fatty acid composition was determined by using the Sherlock Microbial Identification System (version 6.0; MIDI) according to the manufacturer's instructions. The cells were grown on TSA at $28{ }^{\circ} \mathrm{C}$ for 3 days. The fatty acid profile of the organism was characterized by the presence of straight-chain saturated, branched and unsaturated components, as follows (where each of the following constituted $>1 \%$ of the total): iso- $\mathrm{C}_{16: 0}(21.2 \%)$, $\mathrm{C}_{17: 1} \omega 8 c(15.5 \%)$, iso- $\mathrm{C}_{15: 0}(13.7 \%), \mathrm{C}_{15: 0}(7.2 \%), 10-$ methyl $\mathrm{C}_{17: 0}(6.5 \%)$, anteiso- $\mathrm{C}_{17: 0}(5.5 \%), \mathrm{C}_{15: 1} \omega 6 c$ $(4.4 \%), \mathrm{C}_{17: 0} \quad(4.1 \%)$, anteiso- $\mathrm{C}_{15: 0}(2.9 \%), \mathrm{C}_{16: 0}$ $(2.8 \%), \quad \mathrm{C}_{18: 0} \quad(2.8 \%), \quad \mathrm{C}_{16: 1} \quad(2.6 \%), \quad 10$-methyl $\mathrm{C}_{16: 0}(1.8 \%)$, iso- $\mathrm{C}_{14: 0}(1.4 \%), \mathrm{C}_{17: 0} \quad 3-\mathrm{OH} \quad(1.3 \%)$, anteiso- $\mathrm{C}_{17: 1} \omega 9 c(1.1 \%), \mathrm{C}_{12: 1}(1.1 \%)$ and a mixture of $\mathrm{C}_{16: 1} \omega 7 c$ and/or iso- $\mathrm{C}_{15: 0} 2-\mathrm{OH}(1.7 \%)$.

The results of the phylogenetic analyses show that the phylogenetic position of strain R-Ac $013^{\mathrm{T}}$ within the family Intrasporangiaceae varies according to the method applied. In terms of 16S rRNA gene sequence similarity, the closest phylogenetic neighbour was Tetrasphaera japonica (97.1\% similarity), but it differs significantly from strain R-Ac0 $013^{\mathrm{T}}$ in that it has meso-DAP in its peptidoglycan and has an unknown aminophospholipid and phosphatidylglycerol in its polar lipid profile, but does not have $\mathrm{C}_{17: 1} \omega 8 c$ and iso$\mathrm{C}_{15: 0}$ as its major fatty acids (Table 1). Of the other phylogenetically close neighbours, the other species of the genus Tetrasphaera (Hanada et al., 2002; McKenzie et al., 2006) and the genera Janibacter, Knoellia and Oryzihumus are clearly distinguishable from strain R-Ac013 ${ }^{\mathrm{T}}$ by the fact that they contain meso-DAP as the diagnostic diamino acid and/or from the polar lipid profiles (Table 1). On the other hand, the LL-DAP-containing strain Intrasporangium calvum DSM $43043^{\mathrm{T}}$ (Kalakoutskii et al., 1967; Schumann et al., 1997) differs from the isolate in showing hyphal growth, in having MK-8 as the major menaquinone and in terms of its polar lipid profile. The genus Terrabacter (Collins et al., 1989; Montero-Barrientos et al., 2005) comprises long rods or shows a rod/coccus life cycle, whereas the cells of strain R$A c 013^{\mathrm{T}}$ are coccoid in shape. In addition, the genus Terrabacter, together with Terracoccus luteus, can be differentiated from strain $\mathrm{R}-\mathrm{Ac} 013^{\mathrm{T}}$ in that they have phosphatidylethanolamine as the diagnostic phospholipid and lack $\mathrm{C}_{17: 1} \omega 8 c$ as a major fatty acid (Prauser et al., 1997). Differential phenotypic characteristics of strain R-Ac013 ${ }^{\mathrm{T}}$ and related taxa in the family Intrasporangiaceae are given in Table 1. The results of the chemotaxonomic and phylogenetic analyses strongly suggest that strain $\mathrm{R}-\mathrm{Ac} 013^{\mathrm{T}}$ does not belong to any genera (with validly published names) within the family Intrasporangiaceae.

On the basis of the phenotypic and phylogenetic data presented in this study, strain R-Ac013 ${ }^{\mathrm{T}}$ represents a novel genus and species within the family Intrasporangiaceae, for which the name Lapillicoccus jejuensis gen. nov., sp. nov. is proposed.

\section{Description of Lapillicoccus gen. nov.}

Lapillicoccus (La.pil.li.coc'cus. L. masc. n. lapillus a little stone; N.L. masc. n. coccus coccus; N.L. masc. n. Lapillicoccus a coccus attached to a little stone).

Cells are aerobic, Gram-positive, oxidase-negative, catalase-positive, non-endospore-forming, non-motile cocci $(0.2-0.3 \mu \mathrm{m}$ in diameter) that occur singly or in pairs. The diagnostic diamino acid in the cell wall is LL-DAP. The acyl type of the muramic acid is acetylated. Mycolic acids are not present. MK- $8\left(\mathrm{H}_{4}\right)$ is the major menaquinone. Polar lipid profile comprises diphosphatidylglycerol and phosphatidylinositol. Phylogenetically, the genus belongs to the family Intrasporangiaceae, suborder Micrococcineae. The type species is Lapillicoccus jejuensis. 
Table 1. Differential characteristics between strain $\mathrm{R}-\mathrm{Ac} 013^{\top}$ and related taxa of the family Intrasporangiaceae

Taxa: 1, strain R-Ac013 ${ }^{\mathrm{T}}$ (Lapillicoccus jejuensis sp. nov.); 2, Intrasporangium (data from Kalakoutskii et al., 1967; Schumann et al., 1997; Groth et al., 2001); 3, Janibacter (Martin et al., 1997; Yoon et al., 2004; Kämpfer et al., 2006); 4, Knoellia (Groth et al., 2002); 5, Oryzihumus leptocrescens KV628 ${ }^{\mathrm{T}}$ (Kageyama et al., 2005); 6, Terrabacter (Collins et al., 1989; Montero-Barrientos et al., 2005); 7, Terracoccus (Prauser et al., 1997); 8, Tetrasphaera japonica $\mathrm{T} 1-\mathrm{X}^{\mathrm{T}}$ (Maszenan et al., 2000). ND, Not determined.

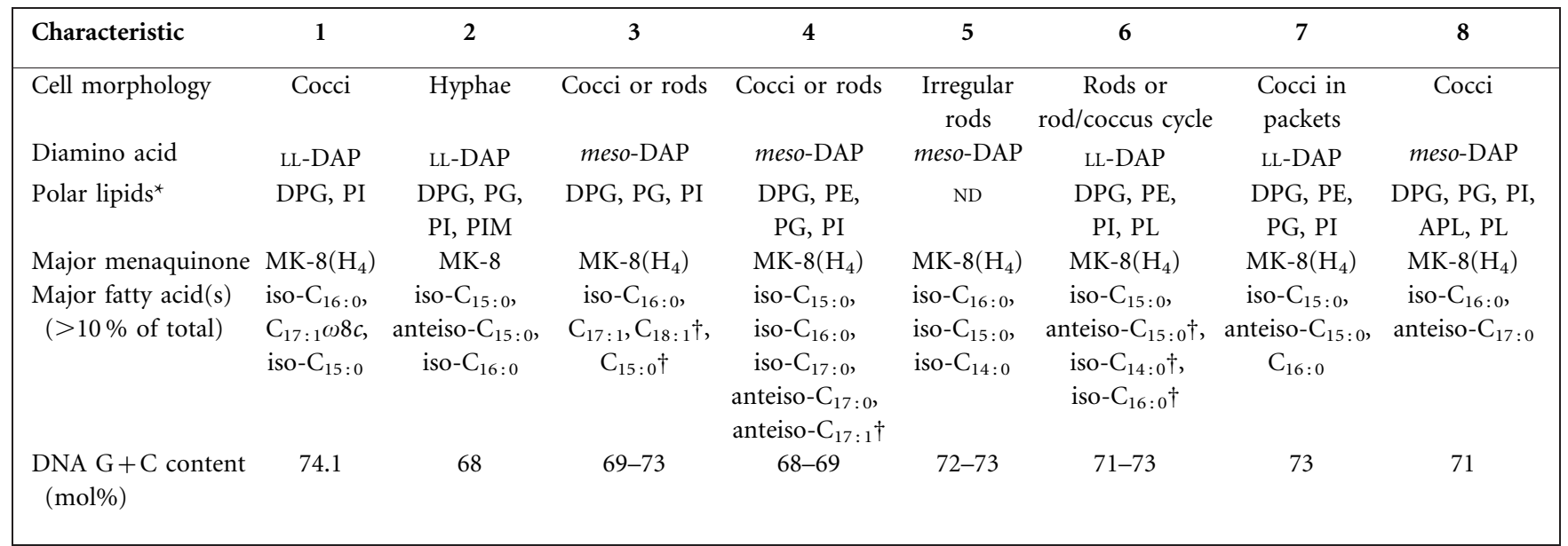

*APL, Unknown aminophospholipid; DPG, diphosphatidylglycerol; PE, phosphatidylethanolamine; PG, phosphatidylglycerol; PI, phosphatidylinositol; PIM, phosphatidylinositol mannoside; PL, unknown phospholipid.

$\dagger$ May also be present, depending on the species.

\section{Description of Lapillicoccus jejuensis sp. nov.}

Lapillicoccus jejuensis (je.ju.en'sis. N.L. masc. adj. jejuensis of Jeju, Republic of Korea, referring to the site from which the type strain was isolated).

The morphological and chemotaxonomic characteristics are the same as those given in the genus description. Colonies are circular, flat, undulate and bright yellow in colour. Temperature and $\mathrm{pH}$ ranges for growth are 20$37{ }^{\circ} \mathrm{C}$ and $\mathrm{pH}$ 4.1-11.1, with optima at $30^{\circ} \mathrm{C}$ and $\mathrm{pH}$ 7.1. No growth occurs below $10{ }^{\circ} \mathrm{C}$, above $42{ }^{\circ} \mathrm{C}$ or at $\mathrm{pH} 12.1$. Growth occurs in the presence of $0-2 \% \mathrm{NaCl}$, but not with $3 \% \mathrm{NaCl}$. $\beta$-Galactosidase is present, but urease and arginine dihydrolase are absent. Nitrate is not reduced to nitrite. Aesculin degradation is observed, but indole production, glucose fermentation and gelatin hydrolysis are not. D-Arabinose, D-mannitol and malate are assimilated or weakly assimilated, but the following substrates are not assimilated: D-glucose, D-mannose, $\mathrm{N}$-acetyl-D-glucosamine, maltose, gluconate, caprate, adipate, citrate and phenylacetate (API 20NE). Protease, cellulase and amylase activities are present. DNA is hydrolysed. Hypoxanthine, tyrosine and xanthine are degraded. In API ZYM tests, the results for leucine arylamidase, acid phosphatase, $\alpha$ glucosidase and $N$-acetyl- $\beta$-glucosaminidase are positive. Results for esterase lipase (C8) and $\alpha$-chymotrypsin are weakly positive. Results for alkaline phosphatase, esterase (C4), lipase (C14), valine arylamidase, cystine arylamidase, trypsin, naphthol-AS-BI-phosphohydrolase, $\alpha$-galactosidase, $\beta$-glucosidase, $\beta$-glucuronidase, $\alpha$-mannosidase and $\alpha$-fucosidase are negative. Major fatty acids are iso- $C_{16: 0}$
$(21.2 \%), \mathrm{C}_{17: 1} \omega 8 c(15.5 \%)$ and iso- $\mathrm{C}_{15: 0}(13.7 \%)$. The DNA $\mathrm{G}+\mathrm{C}$ content of the type strain is $74.1 \mathrm{~mol} \%$.

The type strain, R-Ac013 ${ }^{\mathrm{T}} \quad\left(=\mathrm{KCTC} \quad 19200^{\mathrm{T}}=\mathrm{DSM}\right.$ $18607^{\mathrm{T}}$ ), was isolated from a small stone collected from an agricultural field in Jeju, Republic of Korea.

\section{Acknowledgements}

This work was supported by the 21C Frontier Microbial Genomics and Application Center Program, Ministry of Science and Technology, Republic of Korea. The authors are indebted to Ji Hye Kim for technical assistance.

\section{References}

Collins, M. D., Dorsch, M. \& Stackebrandt, E. (1989). Transfer of Pimelobacter tumescens to Terrabacter gen. nov. as Terrabacter tumescens comb. nov. and of Pimelobacter jensenii to Nocardioides as Nocardioides jensenii comb. nov. Int J Syst Bacteriol 39, 1-6.

Collins, M. D., Routh, J., Saraswathy, A., Lawson, P. A., Schumann, P., Welinder-Olsson, C. \& Falsen, E. (2004). Arsenicicoccus bolidensis gen. nov., sp. nov., a novel actinomycete isolated from contaminated lake sediment. Int J Syst Evol Microbiol 54, 605-608.

Felsenstein, J. (1981). Evolutionary trees from DNA sequences: a maximum likelihood approach. J Mol Evol 17, 368-376.

Felsenstein, J. (1985). Confidence limits on phylogenies: an approach using the bootstrap. Evolution 39, 783-791.

Fitch, W. M. (1971). Towards defining the course of evolution: minimum change for a specific tree topology. Syst Zool 20, 406-416.

Groth, I., Schumann, P., Weiss, N., Schuetze, B., Augsten, K. \& Stackebrandt, E. (2001). Ornithinimicrobium humiphilum gen. nov., 
sp. nov., a novel soil actinomycete with L-ornithine in the peptidoglycan. Int J Syst Evol Microbiol 51, 81-87.

Groth, I., Schumann, P., Schütze, B., Augsten, K. \& Stackebrandt, E. (2002). Knoellia sinensis gen. nov., sp. nov. and Knoellia subterranea sp. nov., two novel actinobacteria isolated from a cave. Int J Syst Evol Microbiol 52, 77-84.

Hanada, S., Liu, W.-T., Shintani, T., Kamagata, Y. \& Nakamura, K. (2002). Tetrasphaera elongata sp. nov., a polyphosphate-accumulating bacterium isolated from activated sludge. Int J Syst Evol Microbiol 52, $883-887$.

Jukes, T. H. \& Cantor, C. R. (1969). Evolution of protein molecules. In Mammalian Protein Metabolism, vol. 3, pp. 21-132. Edited by H. N. Munro. New York: Academic Press.

Jung, S.-Y., Kim, H.-S., Song, J.-J., Lee, S.-G., Oh, T.-K. \& Yoon, J.-H. (2006). Kribbia dieselivorans gen. nov., sp. nov., a novel member of the family Intrasporangiaceae. Int J Syst Evol Microbiol 56, 2427-2432.

Kageyama, A., Takahashi, Y., Seki, T., Tomoda, H. \& Ōmura, S. (2005). Oryzihumus leptocrescens gen. nov., sp. nov. Int J Syst Evol Microbiol 55, 2555-2559.

Kalakoutskii, L. V., Kirillova, I. P. \& Krassilnikov, N. A. (1967). A new genus of the Actinomycetales-Intrasporangium gen. nov. J Gen Microbiol 48, 79-85.

Kämpfer, P., Terenius, O., Lindh, J. M. \& Faye, I. (2006). Janibacter anophelis sp. nov., isolated from the midgut of Anopheles arabiensis. Int J Syst Evol Microbiol 56, 389-392.

Kuester, E. \& Williams, S. T. (1964). Selection of media for isolation of streptomycetes. Nature 202, 928-929.

Lee, S. D. (2006). Phycicoccus jejuensis gen. nov., sp. nov., an actinomycete isolated from seaweed. Int J Syst Evol Microbiol 56, 2369-2373.

Lee, S. D. \& Jeong, H. S. (2006). Actinomadura hallensis sp. nov., a novel actinomycete isolated from Mt. Halla in Korea. Int J Syst Evol Microbiol 56, 259-264.

Martin, K., Schumann, P., Rainey, F. A., Schuetze, B. \& Groth, I. (1997). Janibacter limosus gen. nov., sp. nov., a new actinomycete with meso-diaminopimelic acid in the cell wall. Int J Syst Bacteriol 47, 529-534.

Maszenan, A. M., Seviour, R. J., Patel, B. K. C., Schumann, P., Burghardt, J., Tokiwa, Y. \& Stratton, H. M. (2000). Three isolates of novel polyphosphate-accumulating Gram-positive cocci, obtained from activated sludge, belong to a new genus, Tetrasphaera gen. nov., and description of two species, Tetrasphaera japonica sp. nov. and
Tetrasphaera australiensis sp. nov. Int J Syst Evol Microbiol 50, 593-603.

McKenzie, C. M., Seviour, E. M., Schumann, P., Maszenan, A. M., Liu, J.-R., Webb, R. I., Monis, P., Saint, C. P., Steiner, U. \& Seviour, R. J. (2006). Isolates of 'Candidatus Nostocoida limicola' Blackall et al. 2000 should be described as three novel species of the genus Tetrasphaera, as Tetrasphaera jenkinsii sp. nov., Tetrasphaera vanveenii sp. nov. and Tetrasphaera veronensis sp. nov. Int J Syst Evol Microbiol 56, 2279-2290.

Mesbah, M., Premachandran, U. \& Whitman, W. B. (1989). Precise measurement of the $\mathrm{G}+\mathrm{C}$ content of deoxyribonucleic acid by highperformance liquid chromatography. Int J Syst Bacteriol 39, 159-167.

Montero-Barrientos, M., Rivas, R., Velázquez, E., Monte, E. \& Roig, M. G. (2005). Terrabacter terrae sp. nov., a novel actinomycete isolated from soil in Spain. Int J Syst Evol Microbiol 55, 2491-2495.

Prauser, H., Schumann, P., Rainey, F. A., Kroppenstedt, R. M. \& Stackebrandt, E. (1997). Terracoccus luteus gen. nov., sp. nov., an LLdiaminopimelic acid-containing coccoid actinomycete from soil. Int $J$ Syst Bacteriol 47, 1218-1224.

Saitou, N. \& Nei, M. (1987). The neighbor-joining method: a new method for reconstructing phylogenetic trees. Mol Biol Evol 4, 406-425.

Schumann, P., Prauser, H., Rainey, F. A., Stackebrandt, E. \& Hirsch, P. (1997). Friedmanniella antarctica gen. nov., sp. nov., an LL-diaminopimelic acid-containing actinomycete from Antarctic sandstone. Int $J$ Syst Bacteriol 47, 278-283.

Shirling, E. B. \& Gottlieb, D. (1966). Methods for characterization of Streptomyces species. Int J Syst Bacteriol 16, 313-340.

Stackebrandt, E. \& Schumann, P. (2000). Description of Bogoriellaceae fam. nov., Dermacoccaceae fam. nov., Rarobacteraceae fam. nov. and Sanguibacteraceae fam. nov. and emendation of some families of the suborder Micrococcineae. Int J Syst Evol Microbiol 50, 1279-1285.

Stackebrandt, E., Rainey, F. A. \& Ward-Rainey, N. L. (1997). Proposal for a new hierarchic classification system, Actinobacteria classis nov. Int J Syst Bacteriol 47, 479-491.

Thompson, J. D., Gibson, T. J., Plewniak, F., Jeanmougin, F. \& Higgins, D. G. (1997). The CLUSTAL_X windows interface: flexible strategies for multiple sequence alignment aided by quality analysis tools. Nucleic Acids Res 25, 4876-4882.

Yoon, J.-H., Lee, H. B., Yeo, S.-H. \& Choi, J.-E. (2004). Janibacter melonis sp. nov., isolated from abnormally spoiled oriental melon in Korea. Int J Syst Evol Microbiol 54, 1975-1980. 